\title{
8 Introducing the Bible: The Comparative Orientation in Practice
}

Jon A. Levisohn

\section{Introduction}

Much of what we "know" about how Bible is taught is anecdotal, based on our own experiences or limited impressions of the experiences of others. What systematic knowledge do we have about what is important to teachers of Bible in different settings? About the decisions teachers make, and on what basis? About what teaching Bible actually looks like? In his chapter above, Barry Holtz takes an important step forward ${ }^{1}$ by establishing an organizational scheme for the variety of approaches or "orientations" to the teaching of Bible. ${ }^{2}$ In the short time since its publication, Holtz's language of orientations has become a standard for those who write and teach about teaching Bible. ${ }^{3}$

But beyond providing vocabulary, Holtz's identification of different orientations or approaches to teaching Bible enables us to ask deeper and richer questions about those approaches. This paper is an effort to do that kind of exploratory work within one orientation, the Contextual Orientation. In this approach to the teaching of Bible, most common in academic settings, the teacher strives to present the texts

1 Barry Holtz, Textual Knowledge: Teaching the Bible in Theory and Practice (New York: JTS Press, 2003).

2 See chapter 2 in this volume. For further exploration of the concept of an orientation, see chapter 3 above, in which the concept is extended to rabbinic literature.

3 Holtz deals exclusively with the Hebrew Bible or Tanakh, as will I. It is of course true that "Bible" means different things to different people, itself an important pedagogical topic. But for the purpose of this chapter, I will simply use "Bible" to refer to the Hebrew Bible. 
of the Bible in their original context, and to promote the students' understanding of their original meaning through modern, critical scholarship. As Holtz writes, "It views the Bible as a record of an ancient civilization, and it hopes to make that world intelligible to students of today." 4

This is fine, so far as it goes. The Contextual Orientation, by seeking the meaning that obtained at one particular (distant) time, is not concerned with discerning a trans-historical and eternal meaning. ${ }^{5}$ It also rejects the notion of the unity of the text that serves as a cornerstone not only for traditional interpretation (in which discrepancies are midrashically harmonized) but also for contemporary literary critical interpretation.

But what actually happens within the Contextual Orientation? How does a teacher committed to this orientation articulate the premises of the orientation to an audience of students? What are the key pedagogical objectives for a teacher within this orientation, and how does he or she accomplish those objectives? What are the options within the orientation, and what choices do teachers have to make? My agenda in this chapter, most broadly, is to argue that the identification of various distinct orientations is only the first step towards a robust exploration of the modes and methods of teaching Bible, a first step that must be followed by further steps that probe pedagogic practices and purposes far more closely. As William James famously wrote in Varieties of Religious Experience, "A large acquaintance with particulars often makes us wiser than the possession of abstract formulas." 6

4 Chapter 2, p. 33, above.

5 The precise "context" to which the Contextual Orientation refers is actually ambiguous (as we will see, the subject of this study frequently talks about "contexts," in the plural). Is it the original meaning of the original author(s)? Or the meaning as understood by the original audience(s)? Or the meaning as understood by the redactor, or the audience at the time of redaction? For our purposes, however, we need only note the ambiguity without resolving it.

6 William James, The Varieties of Religious Experience [1902] (New York: Penguin, 1982), xxxv. 
This kind of inquiry is important not merely for its own sake but because of its potential to contribute to the improvement of practice. But this chapter does not attempt to identify "best practices." It does not endorse or argue for a particular pedagogic method. Instead, the focus is on deepening our understanding, in the conviction that what teachers need, more than tips and techniques, more than practical advice, is thoughtful understanding of the pedagogic choices and challenges that their chosen subject presents. What can we understand about what happens in the teaching of Bible from the Contextual Orientation? If we look at it closely and linger long enough, what will we see?

To begin to gain some insight into the Contextual Orientation in practice, this paper will examine how "Moshe," a university instructor who is committed to teaching within the Contextual Orientation, introduces the study of Bible to his students. ${ }^{7}$ His introduction is not merely a prologue to his "actual" teaching; on the contrary, it is the pedagogic moment where he articulates what is most important to him about Bible, the occasion for him to frame his teaching approach and identify its significant features. I will compare how he introduces the Bible in two different contexts: first, in his survey course on Bible ("Bible 101") for undergraduates; and second, in the opening session of

7 The analysis is based on videotapes - and transcripts of those videotapes-of Moshe's teaching of the introductory session in the two settings (in the fall of 2005), triangulated through Moshe's review of the analysis and a discussion of the findings with him in a subsequent interview (on May 17, 2006, which will be quoted occasionally below). For more on the methodology of the study, see the longer version of this chapter, Jon A. Levisohn, "Introducing the Contextual Orientation to the Bible: A Comparative Study," Journal of Jewish Education 74:1 (2008): 56-59. The use of a pseudonym requires some explanation, especially since many readers will easily discern the identity of the subject. If his identity is already known, then what is the purpose of pretending to conceal it? More important than protecting anonymity, and more important than following scholarly conventions for educational research, the pseudonym serves another significant function: to signal that, as I will repeat below, the purpose of this paper is not to discover the truth about this particular teacher but to use him as an example in order to explore certain ideas. 
a year-long Jewish adult education course ("Bible for Adults" or "B4A"), which is part of an intensive two-year cycle of study.

\section{A Brief Sketch of the Two Classes}

How does one introduce the Bible within the Contextual Orientation? In the university introduction to Bible, Bible 101, Moshe sits at a desk, dressed in a dark cotton sweater worn over a blue button-down shirt, with a knitted kippah on his head, in front of an open laptop connected to a projector that generates slides on a screen behind him. The class has about 40 students. The university, located in the northeast US, is a research institution that also emphasizes undergraduate teaching. It is non-sectarian, with a large population of Jews. In Bible 101, Moshe estimates that at least $3 / 4$ of the students are Jewish, with a quarter of them traditionally observant (either Conservative or Orthodox).

Moshe begins with some warm-up welcoming sentences, and then opens his argument-the session is framed as a series of arguments, with evidence to support the theses-with a statement about the relevance of the Bible. "I honestly believe," Moshe declares to the students, "that the Bible is an extremely profound text that deals with a set of issues that are still relevant." Developing his argument, Moshe then proceeds to show (on slides projected behind him) particular passages that relate to a series of supposedly relevant issues: first texts that depict God, then texts that discuss death, then texts that are in some sense about gender. After working through these texts for approximately 10 minutes, he then transitions to a methodological discussion about how the Bible will be studied in this course. Finally, after pausing for questions, he shifts his tone and begins to discuss some practical aspects of the course, regarding the syllabus, preparation for class, assessments, and the like.

In the adult education setting, Bible for Adults, Moshe also sits at a desk in a classroom, dressed in a grey button-down shirt and maroon tie, wearing his kippah visible on his head, but without a laptop; instead, he has before him a Tanakh and his notes. Instead of a screen behind him, he has a whiteboard off to his left, on which he writes once or twice during his introduction. While the classroom is located in a 
synagogue, the course itself is communal; in this particular version of the course, almost all of the 20 adult students come from Conservative backgrounds. In this setting, after his warm-up welcome, he explains that the purpose of this first class session is to provide "four contexts" for the course as a whole: the geographical context of the Bible, the historical context, the context of the structures of the Bible, and what he calls the "contexts of interpretation." He then proceeds to work through each of these contexts.

First, the geographical context is actually not just about the location of ancient Israel between the great powers of Mesopotamia and Egypt but, more specifically, about the significance of that geographical location for the self-understanding of ancient Israelites and impact of that self-understanding on their culture and its product, the Bible. Second, in order to provide the historical context, Moshe focuses especially on the standard periodization of ancient Israelite history, i.e., how to sub-divide the overall biblical narrative into units, which he notes is important for the purpose of explaining biblical texts in terms of the historical events to which the author is responding. Third, he explains the "context of the structures of the Bible" by opening up his Tanakh and describing its component parts and their order. And finally, Moshe concludes by tackling the "contexts of interpretation." He describes the traditional interpretive approach to the Bible, which assumes that the text is "privileged," and then proceeds to describe the contrasting, critical interpretive approach that de-privileges the text. Spinoza serves as a model, here, of the interpreter who uses reason rather than tradition as the criterion of meaning. Moshe makes it clear that this course, B4A, will follow Spinoza's lead.

\section{Commonalities Between the Two Settings}

The preceding cursory sketch begins to reveal some important differences between the two courses, most dramatically in terms of the basic structure of the sessions. But before proceeding with a more detailed analysis, I will first spell out the commonalities. First, of course, the instructor is the same person, with the same intellectual background, and presumably, the same core commitments. 
In addition, three pedagogic values ${ }^{8}$ appear in each. In each setting, Moshe is aware of the potentially problematic nature of the subject, or rather, of his approach to the subject, and he acknowledges this difficulty in both settings. In each setting, Moshe is not satisfied talking about texts, but instead quickly turns to texts themselves in order to show them to the students. We might call this pedagogic value the centrality of text. And in each setting, Moshe is not afraid to express his own voice in the classroom, making his presence felt as a student of the text, and as a person. We might call this his use of personal voice.

Alongside these three pedagogic values, there are four distinct (but related) pedagogical objectives that are common to both settings as well. First, Moshe wants students to appreciate the internal diversity of the text. Second, Moshe sees his role as subverting preconceptions that students bring to the text. ${ }^{9}$ Third, Moshe wants his students to establish some critical distance from the text. But fourth, surprisingly, there is evidence in each setting that Moshe explicitly preserves the possibility of personal meaning; that is, he finds ways to make room for students to establish or maintain personal connections to the text, despite the obvious tension between this kind of connection and the Contextual Orientation within which he teaches.

8 I am using "values" somewhat loosely, to signal a sphere that is distinct from Moshe's subject matter knowledge on the one hand and from his objectives on the other (addressed below). Within this sphere, I am identifying three pedagogic practices that are not mere techniques or strategies but that seem to represent some deeper convictions about teaching this specific subject.

9 There are a number of possible reasons for this. It may be that the subversion of preconceptions functions as a feature of the Contextual Orientation, given the role that the Bible plays in the religious lives of some students. It may be that subverting preconceptions is a helpful technique to use in an introductory session, when a teacher is trying to engage his students in the course of study ahead of them (in other words, subverting preconceptions is a strategy for hooking students on the subject and for getting them to return to the course). Finally, it may be that subverting preconceptions is a productive pedagogic technique to use in general, perhaps because real learning only occurs when one's prior expectations are disrupted (in which case subverting preconceptions is not a specific feature of the Contextual Orientation, nor is it a technique especially helpful for introductory sessions, but instead is always the goal of good teaching in general). 
The following chart (figure 1) recapitulates the commonalities between the two settings.

\begin{tabular}{|l|l|}
\hline $\begin{array}{l}\text { Moshe's subject matter } \\
\text { knowledge and beliefs }\end{array}$ & $\begin{array}{l}\cdot \text { Knowledge of and about Bible } \\
\text { - Commitment to Contextual Orientation }\end{array}$ \\
\hline $\begin{array}{l}\text { Moshe's pedagogic } \\
\text { values }\end{array}$ & $\begin{array}{l}\text { A. Awareness of problematic nature of the subject } \\
\text { B. Centrality of text } \\
\text { C. Use of personal voice }\end{array}$ \\
\hline $\begin{array}{l}\text { Moshe's pedagogical } \\
\text { objectives }\end{array}$ & $\begin{array}{l}\text { 1. Fostering appreciation of internal diversity of } \\
\text { the text } \\
\text { 2. Subverting preconceptions about the text } \\
\text { 3. Establishing critical distance from the text } \\
\text { 4. Preserving the possibility of personal meaning }\end{array}$ \\
\hline
\end{tabular}

Figure 1: Commonalities between the two settings

The first category, regarding the instructor's knowledge and commitments, is straightforward (and I have only marked it by bullets in the chart above, as we will not be referring back to it directly). But in order to supply evidence for the commonalities in the second and third categories ("values" and "objectives"), in particular to demonstrate how Moshe strives to accomplish the four key objectives, and most generally to provide the kind of thick description that can help the reader understand Moshe's teaching in greater depth, I will now turn to a closer analysis of selected moments in each of the two sessions.

\section{Introducing the Bible in Bible 101: A Closer Analysis}

Moshe begins Bible 101 with a statement about the Bible as a source of answers to important questions.

The real reason that interests me, and will interest us throughout this class, is that I honestly believe that the Bible is an extremely profound text, that deals with a set of issues that are still relevant. Issues such as: how and why should one bother living? How should 
one die? What's the proper way to treat other people? What is the Other? ... [The Bible] almost never has a single answer.

Thus, he begins with an emphasis on profundity and relevance: the issues that he raises are profound ones, i.e., they are fundamental human-existential questions that are eternally relevant. Moshe suggests, although he doesn't actually say it here, that the answers that one finds in the Bible to these questions may be equally profound.

Three analytical points are important here. First, it seems particularly significant that Moshe opens by introducing the idea that students of the Bible may find personal meaning in the text-preserving the possibility of personal meaning - not necessarily religious meaning, but certainly personal existential meaning. As if to anticipate the challenge that the Contextual Orientation robs the text of meaning, Moshe affirms the opposite right at the outset. Second, this emphasis on profundity and relevance is a difference between the university class and the adult education class. While he does preserve the possibility of personal meaning in other ways in B4A (about which more below), he does not suggest that the biblical text deals with profound or relevant issues; that claim is entirely absent. (Perhaps Moshe believes that the students in Bible 101 have to be enticed to stick with the class, in a way that the adult students in B4A do not.) Third, and most importantly, Moshe moves almost immediately from his initial argument about the relevance of the text-an argument about why students ought to study the text-to an argument about how they ought to study it: namely, with an eye towards the internal variation within it.

Thus, the conclusion to the paragraph just quoted- "It almost never has a single answer" - serves as a transition to the next stage, in which Moshe presents passages on God, death, and sex/gender. Each provides Moshe with the opportunity to move from talking about the text to introducing actual texts into the discussion, just a few minutes into the very first class session. As noted above, the centrality of text is clearly important to Moshe's teaching, and each brief set of texts provides an opportunity to demonstrate internal diversity in the Bible.

However, the discussion of the themes of God, death, and gender does more than just foster an appreciation of internal diversity. In the 
course of discussing the biblical view of God, Moshe displays passages from Deuteronomy and Exodus, ${ }^{10}$ and then says:

So when you take the very first text up here, which comes from the book of Deuteronomy, where you have the notion that there is no perceived shape of God-had I given you a pop quiz at the beginning and said, "What does God look like according to the Hebrew Bible?," the odds are relatively good that that is, if not the text, the conception or the preconception that many people might have had.... But compare that text to the second text, from the book of Exodus, where a bunch of people ... see God. It can't be any clearer: "And they saw the God of Israel."

Moshe is promoting the idea, here, of the internal diversity within the Bible on a central theological topic. But he is also implicitly promoting the idea of reading the text in its plain sense, like any other text, without the overlay of (later) theological assumptions. In addition, this passage is an example of the phenomenon to which I referred above, namely, subverting preconceptions: Moshe transitions from describing the diversity of the text to explicitly questioning the preconceptions of the students.

Pausing here to consider this phenomenon, it is possible to identify three distinct ways in which that subversion occurs. First, implicitly, Moshe begins by subverting a possible preconception that the text is irrelevant or antiquated, instead affirming that its issues are profound ones. Second, Moshe then subverts a more significant preconception, namely that the text is unified, by demonstrating the diversity within the text. But third, and most explicitly, he moves towards subverting assumptions about its content-not just about what the Bible is but about what it actually says-by showing passages that contradict those assumptions.

10 The passages are as follows (JPS translation). From Deuteronomy: "The LORD spoke to you out of the fire; you heard the sound of words but perceived no shape-nothing but a voice.... For your own sake, therefore, be most carefulsince you saw no shape when the LORD your God spoke to you at Horeb out of the fire-not to act wickedly and make for yourselves a sculptured image in any likeness whatsoever" (Deut. 4:12-18). From Exodus: "And they saw the God of Israel: under His feet there was the likeness of a pavement of sapphire, like the very sky for purity. Yet He did not raise His hand against the leaders of the Israelites; they beheld God, and they ate and drank" (Exod. 24: 9-11). 
Moshe continues his presentation of passages, but when he gets to the topic of gender, he pauses to acknowledge that some of the passages may be offensive. He then offers a signature line, a line he repeats word for word in B4A: "I teach the Bible; I did not write the Bible. I am not responsible for all of the thoughts that the Bible contains." ${ }^{11}$ The line elicits laughter from the students, and diminishes much of the discomfort in encountering these texts. It accomplishes this by setting up the Bible as a text from which Moshe is able to establish some critical distance. And, of course, he's recommending that the students establish some critical distance as well. Moshe is passionate about the text, and has committed his life to the study of it; he hopes that the students will be able to see that such a life of study is a legitimate option. But he is not responsible for it (or, he is not responsible for all of it). He reserves the right to disavow the text or some aspect of the text. The students should be able to see that that, too, is a legitimate option.

This establishment of critical distance is a central objective of Moshe's teaching. In an interview, ${ }^{12}$ he called it "normalizing the Bible," and said that it is "something that Bible professors need to be doing." It is an aspect of the Contextual Orientation that Holtz does not make explicit, and one that most academics would not think to mention as a hallmark of their methodology because it goes unnoticed, like the air that we breathe.

But how does Moshe actually teach this critical distance? First, he teaches it by calling attention to it. He does not use the term "critical distance" here, but the invocation of limited responsibility for the text is no less powerful. Beyond this, however, note that his formulation is constructed in the first person: "I teach the Bible; I did not write the Bible. I am not responsible for all the thoughts that the Bible contains." In this way, Moshe presents himself as a potential role model for the students. He never says anything as explicit as, "I am not responsible for the all the thoughts that the Bible contains - and neither are you." But the implication is that he, Moshe, is a living model of what it means to relate to the text in this way, to hold it at some critical distance even as one is passionately invested in it and devoted to it. This person standing before you, says Moshe, did not write the Bible-but he does teach it.

11 The italics here represent Moshe's own emphasis.

12 See note 8 above. 
And you students, therefore, should be able to envisage, perhaps for the first time, holding the text at some critical distance even as you commit yourselves to its study, perhaps with a rigor you never imagined possible. ${ }^{13}$

Immediately after offering this signature line, Moshe segues back to his argument about the internal diversity of the text, and then transitions to the final arguments of his introduction. This is an extraordinarily rich passage, so I will quote it at length.

I teach the Bible; I did not write the Bible. I am not responsible for all of the thoughts that the Bible contains.

And the point is, really: all the thoughts that the Bible contains. Because the Bible is a very complex book. And the way in which we are going to explain this complexity in class is the way that complexity would be explained in any class that deals with history or any class that deals with history of religion, namely, to realize that the Bible as a complex text is written over a one thousand year period, in a variety of places, by a variety of people coming from different social settings ... and as such, even though it is included between two covers, there is no reason to assume that there is a fundamental unity to this text.

I want to briefly say something that perhaps I'll come back to later in the semester and that I'm happy to discuss in more detail out of class. It might seem to some of you that the particular position that I am taking concerning the Bible and its origin is an anti-religious position. That is not something that I am intending to do. Rather, I am interested in reading biblical texts closely, within the context, or contexts, of ancient Israel that engendered these particular texts, and using this ancient history, and these ancient backgrounds, to help us explain what the Bible meant.

Thus, if you are listening to me carefully ... one might make a distinction between what the Bible meant and ... what the Bible means. What the Bible means is an issue which is up to every individual; that is a highly personal issue, and in fact the Bible might mean nothing! What the Bible meant is a different issue, and is connected to the fact that this was produced by a particular culture in antiquity. And my interest in this particular class is, by and large, understanding what it meant to that particular culture.

13 "Look," Moshe says in the interview (see note 8), "I hope that they will take the text as seriously as I take it.... I try to convince my students that this is an interesting text and an important text and a dangerous text." 
Having discussed the intellectual issues that he had intended to address in this session, Moshe next turns to procedural issues regarding student responsibilities and so on. These lines, therefore, serve as a conclusion to his substantive introduction to the course.

Four themes emerge from this passage. First, Moshe makes explicit that the point of showing the internal diversity within the biblical texts is to introduce the multiple authorship of the Bible. Second, Moshe inserts a comparison of Bible to other fields, claiming that the method of the course will be just like that of other historical inquiries. This rhetorical move legitimates the study of Bible within the university. The third point of analysis, on the other hand, is a reaction against that very message. The idea of Bible as a field like any other, with no particular special features, is belied by Moshe's attention to the question of whether his approach is "anti-religious." Again, we see Moshe's awareness of the problematic nature of the subject. We also see his use of personal voice. Being anti-religious "is not something I am intending to do," he claims. "Rather," he continues, "I am interested in reading biblical texts closely." The prominence of Moshe's own persona here is striking. Implicitly, Moshe is telling his students that he, Moshe, represents not only a legitimate and religiously neutral pedagogic approach but an approach that they can consider adopting for themselves - that is, a critical position that is not anti-religious.

The fourth and final point of analysis regarding this passage has to do with Moshe's distinction between what the Bible means and what it meant. In a personal communication, Moshe observes that he borrows the distinction from Krister Stendahl. ${ }^{14}$ However, it does not withstand close scrutiny. Consider the fact that "what the Bible meant" is inextricably bound up with "what the Bible means," in part, for at least one person in that room-namely, Moshe himself! This suggests that we cannot neatly demarcate the historical inquiry from the personal search for present (perhaps existential) meaning. Every claim advanced by a historian about the past meaning of the text is also, inevitably, at least in part a claim about the present meaning of the text. Conversely, many claims about what a text means, in the present, that seek to be

14 Personal communication on May 16, 2006, i.e., the day preceding the interview that is cited elsewhere in this chapter. The Stendahl reference is to Krister Stendahl, "Biblical Theology: A Program" [1962], the second chapter in his Meanings: The Bible as Document and as Guide (Philadelphia: Fortress, 1984). 
compelling or persuasive incorporate implicit claims about what it has meant (or could have meant) in the past, at least to some of its hearers and readers. ${ }^{15}$ Moshe himself, it would seem, isn't in fact committed to the meant-means distinction. "The contextual method," he says, "allows ancient meanings to come out with which people can connect in a wide variety of ways." In other words, people will derive contemporary personal meaning from a deeper understanding of what the Bible meant. ${ }^{16}$

But the preceding paragraph is, in the end, a quarrel about hermeneutics. What's important here is that Moshe offers the distinction as an attempt to preserve the possibility of personal meaning, opening the door for those who want to participate in the course but who are worried about the loss of a personal or existential relationship to the text. He is, in other words, attempting to preserve the possibility of personal meaning, even as he explains the commitment to the Contextual Orientation that will guide their study together.

\section{Introducing the Bible in B4A: A Closer Analysis}

The preceding section of this paper offered an analysis of Moshe's teaching in Bible 101, focusing in particular on the data that provides evidence for the common features of Moshe's teaching mentioned above: (A) his awareness of the problematic nature of the subject, (B) his emphasis on the centrality of the text, and $(C)$ his use of personal voice. It also discussed his four pedagogical objectives: (1) fostering an appreciation of internal diversity of the text, (2) subverting preconceptions about the text, (3) establishing critical distance from the text, and (4) preserving the possibility of personal meaning. This section will focus on the same themes in the second setting, Bible for Adults (B4A).

15 Moshe's suggestion that "what the Bible means is an issue which is up to every individual" - as if there were a realm of personal meaning-making that is unconstrained by any demands for arguments and evidence-is well-intentioned but misguided. Of course people do discern idiosyncratic meanings, but those meanings are no more justified than equally idiosyncratic claims about historical meaning.

16 Compare Holtz's characterization of the Contextual Orientation, that it "hopes to make that [ancient] world intelligible to students of today" (Holtz, Textual Knowledge, 92). In Moshe's view, the Contextual Orientation aspires to far more than intelligibility; it provides some of the grounds for personal connection. 
As noted in the brief overview of this class above, Moshe adopts a different approach to the introduction of the Bible in B4A than he does in Bible 101. He does not entice these students with the promise that the Bible deals with profound and relevant issues as he did for the college students; he does not address their preconceptions directly as he did by sharing various texts about God; he does not introduce and emphasize the internal diversity within the Bible here as he did there. Instead, he opens by offering a clear and explicit outline of the session, in which he will discuss "four contexts" for the course as a whole. These contexts are the geographical context, the historical context, the context of the structure of the Bible, and what he calls "the contexts of interpretation."

The structure of the opening session may seem rather dry and academic, apparently ignoring the pedagogic values and objectives emphasized above. But this is not the case. In fact, the very first element-the Geographical Context-turns out to be crucially important for Moshe's purposes in teaching within the Contextual Orientation. He does offer a clear-cut description of the geographical location of ancient Israel, but he quickly moves from geographical facts to the significance of those facts.

As he begins to explain that significance, he calls attention to what he is about to say in an extraordinary way. "I'm going to make a claim which is going to sound a little odd," he says, "but it is true." He then calls even further attention to his claim: "Unless you remember that it is true, you're not going to be able to appreciate the Bible." So this claim is not only odd, and not only true, but crucially important! What is this claim?

The claim is very simple: Israel is a small hick country, a latecomer into the world of antiquity, and it is stuck between the two great imperial powers, the power of Mesopotamia and the power of Egypt.

Thus, the important but simple claim is a claim about what ancient Israel was, as a political and cultural entity, from an objective perspective, independent of how it conceived of itself or how those with some familial or religious connections to ancient Israel (in this case, Jews) might conceive of it today.

Why is this claim so important? Why does Moshe emphasize it to such a degree? The claim is important because it represents the kind of 
objectivity that is a hallmark of Contextualism, which is attuned not only to the objective value of the text but also strives for an objective characterization of the historical periods that the text depicts. Thus, it serves one of his main pedagogic objectives, namely, establishing critical distance. It does so in a less subtle way than by declaring "I am not responsible for all the thoughts that the Bible contains." And indeed, the critical distance that it establishes here in B4A is not precisely identical with the critical distance established by Moshe's signature line in Bible 101. In the latter case, the denial of responsibility for the entirety of the text opens up the possibility that some aspects of the texts-some laws or some moral positions or perspectives-are or ought to be subject to critique. In $\mathrm{B} 4 \mathrm{~A}$, on the other hand, the critical distance is rather a matter of calling into question the self-representation of the text, of beginning to develop a hermeneutics of suspicion. ${ }^{17}$

How does this work? The ideas of Israel as "hick" and a "latecomer," ideas that Moshe clearly assumes are new to the students, are not of course present in the biblical text. These are not the kind of characterizations that a nation declares about itself: they are too negative, and more importantly, they are characterizations that place the subject on the periphery rather than at the center. However, once one begins to think more objectively about ancient Israel, one is now open to the possibility of asking the all-important question, "Why would the biblical author have written (or believed) this?" The naiveté of accepting the biblical account and the biblical perspective at face value is undermined, if not immediately shattered. The text now becomes a political document, a text that bolsters certain ideological positions in ancient Israel and undermines others, a text that is doing something, not merely saying something.

But Moshe does not merely emphasize the importance of this claim; he prefaces it by acknowledging that it is going to sound odd to the stu-

17 The phrase "hermeneutics of suspicion" first appears in Paul Ricoeur, Freud and Philosophy, trans. Denis Savage (New Haven: Yale University Press, 1970), 32, who used it to refer to a mode of interpretation represented especially by Nietzsche, Marx, and Freud, in which the interpreter assumes that the surface or naïve meaning of a text (or a person's utterances) mask a deeper political or sexual meaning. This mode of interpretation has its excesses, to be sure, but fundamentally, the stance of suspicion about the self-representation of a text is a hallmark of any critical inquiry. 
dents. He recognizes the problematic nature of the subject matter. The students may not realize, at first, the implications of the innocuous statement, "Israel is a latecomer nation," but Moshe knows its significance: he knows that this will be a new idea for them, one which will not fit with their prior understanding of the place of Israel in the Ancient Near East. In other words, he is also engaged here in subverting preconceptions. To be more precise, he is subverting a specific preconception about the centrality of Israel on the world stage as well as a general preconception about the reliability of the self-presentation of biblical texts.

And as he continues, a third preconception emerges, this time quite explicitly.

If anyone grew up with the idea that Israel is the first great society, or ... the first great writing society, or that there is nothing comparable to Israelite literature, Israelite philosophy, Israelite religious notions in the ancient Near East, the function of the next 10 to 15 minutes is to disabuse you of any of those notions.

The specific preconception here is the notion of Israel's unique cultural creativity or religious genius. Preconceptions such as these may have been part of the students' childhood, parochial notions instilled through Jewish education or worship.

Moshe then pauses, trying to help the students see what they're supposed to be learning.

And really, what ... this class is about, is not proving that Israel is better ... but rather to help you focus on what the Bible meant in its original context.

Moshe thus declares his allegiance to Contextualism, at the same time echoing the distinction that he offered in Bible 101 by invoking the idea of "what the Bible meant" as the goal of the class. This course, $\mathrm{B} 4 \mathrm{~A}$, has a goal that stands in opposition to what might typically be considered appropriate for a Jewish educational setting. Moshe is not interested in claims of the literary or religious superiority of the Bible or of ancient Israel; he is apparently not interested in promoting personal connections to the text (although I will have more to say about this below). He is simply interested in original meanings. 
But how does a teacher actually subvert preconceptions about the uniqueness of ancient Israel? Moshe's technique is to introduce students to other sources, demonstrating his commitment to the centrality of texts-not just talking about texts but engaging with texts directly. He introduces some Ancient Near Eastern prayers in order to show similarities to and differences from concepts that are familiar to his students from the Jewish tradition, concepts such as food taboos and sacred space. He then concludes this section by reiterating his argument: "Literarily, technologically - to say it one last time-Israel was a latecomer into a world dominated by the two great civilizations of Mesopotamia and Egypt." Geographical context, it turns out, is much more than reading the map.

Moshe's discussion of the second and third contexts (the historical context and the context of the structure of the Bible) does not add to the present analysis, with the exception of one moment that is worth describing carefully. It's a moment that does not, at first, seem particularly notable. How, he asks, should the word "Torah" be translated?

Torah ... should not be translated as "law" but should be translated as "instruction." This might sound overly pedantic, but I think this is actually quite important. Obviously, the Torah is not all law; look at the book of Genesis! ... Understanding Torah as law by and large is a Protestant notion which Jews should not adopt. And "instruction," which has law as a subset within it, is probably a better and more accurate understanding of Torah, because narratives ... can instruct in the same way as laws can instruct.

As above, with the claim about Israel as a latecomer nation, so too here he calls attention to his point, signaling that it not merely pedantic. But why is it so important?

When viewed through the lens of the analysis of Moshe's Contextualism, what's important about this point is its normativity, the way in which he is advancing a particular norm of behavior. He is not just presenting a sound scholarly argument about a point of translation (although his point about the Genesis narratives is clear); he is advocating for the usage of the translation "instruction," and against the translation "law." And the normativity passes over from the exclusively intellectual to the moral or religious. "Jews should not adopt [this notion]," 
he declares. It's not just that it's false. There's something here that is central to the way that Jews should read and relate to this text.

Why should Jews conceive of Torah as instruction rather than law? Moshe likely has in mind the Christian conception of Judaism as a religion of law (as opposed to Christianity, a religion of love). Jews, he is saying, ought not to internalize this canard. But there is a deeper point here, and a more positive one: namely, that Jews ought to relate to the Bible as book of instruction in a broader and more subtle sense than merely a set of laws to be followed. "Narratives ... can instruct in the same way as laws can instruct." Moshe is saying here that this is a text from which one can learn. And furthermore, in some sense, the students ought to learn from it, or at least, they ought to know that they can learn from it. Moshe, standing at the front of the room with a kippah on his head, is making a case that the Torah not only was a book of instruction but indeed can still be so. ${ }^{18}$

This is only a brief moment in the class, but it doesn't take much for a teacher to set a tone, to establish norms, to communicate values. The norm in this case has to do with an attitude toward the Bible that seems to contradict the conventional wisdom about critical biblical scholarship and the teaching of it, according to which it is committed not merely to objectivity or neutrality, but rather to a kind of cynicism about personal meaning. For academic scholars, it is sometimes said, the Bible is just another Ancient Near Eastern text. But here we glimpse an attitude of reverence, a shortening of critical distance, an erosion of cool objectivity. Biblical texts, according to this norm, are texts with which the students ought to engage from a stance of commitment-not necessarily texts to which they should be subservient, but nevertheless texts from which the students ought to learn or to which they ought to be connected. The establishment of this norm surely preserves the possibility of personal meaning. ${ }^{19}$

18 In a personal communication (May 16, 2006), Moshe affirms the interpretation offered here, and expands on the point: "Part of the point of Torah as instruction ... reflects an interest in getting away from Torah as history, and planting the seed of an idea that fiction can instruct as effectively as, or more effectively than, non-fiction."

19 In the interview (see note 8), Moshe makes the point explicitly, in terms of the establishment of a relationship: "The whole point of ... a lot of my teaching is to show that the contextual method is useful ... for creating a relationship between the text and the life of today." 
Finally, Moshe turns to what he has called the "context of interpretation." Here he discusses the traditional idea of Bible as "privileged literature," that is, literature that is exempt from standard interpretive techniques according to which the plain sense of the text is assumed to be its meaning. He illustrates the idea by sharing examples of contradictions in the biblical text that are harmonized by midrashic interpretation. Thus, this section represents again Moshe's commitment to the pedagogical objective of fostering an appreciation of the diversity of the text. But the rabbis, Moshe explains, who are committed to Bible as privileged literature, are compelled to abandon plain-sense readings. (Of course, what exactly constitutes the "plain sense" or "privileging" in any particular case is surely a complicated issue, which we cannot pursue here.)

Having explained the idea of the Bible as privileged literature, Moshe's next step is to indicate what happened to that idea, by turning to Spinoza. Why Spinoza rather than, say, Wellhausen or perhaps Hobbes? ${ }^{20}$ In part, this is because he is not trying to explain the Documentary Hypothesis in particular, but rather the more general approach of interpreting Bible as one would interpret any text (that is, of de-privileging the text). But aside from that, Moshe is calling on Spinoza as a Jew-not the most successful Jew, perhaps, but a fellow Jew nonetheless, and one whom these adult Jewish learners ought to embrace. He makes a point of calling Spinoza by his Hebrew name, "Baruch."

The key line from Spinoza's Theological-Political Treatise is the following: "I hold that the method of interpreting scripture is no different than the method of interpreting nature." Moshe does not focus on what "interpreting nature" meant within Spinoza's philosophical system; neither will I. Instead, I will merely note that the comparison of the study of Bible to the study of nature recalls a rhetorical move that he made in Bible 101, when he compared his approach to "any class that deals with history or any class that deals with history of religion." At least in

20 Benedict Spinoza (1632-1677) argued, in his Tractatus Theologico-Politicus (1670), against the Mosaic authorship of the Bible, as had Thomas Hobbes (1588-1675) a bit earlier in his Leviathan (1651). Both of these books are not primarily works of biblical scholarship, however, but rather political philosophy. Julius Wellhausen (1844-1918) is generally credited with the development of the Documentary Hypothesis in his Prolegomenon to the History of Israel (1886). 
certain respects, the study of Bible within the Contextual Orientation is no different than the academic study of anything else.

However, Moshe moves immediately from rejecting the idea that the study of Bible is special, to a dramatic use of personal voice that attenuates that very point.

What Spinoza is insisting on, almost for the first time, is that for interpreting the Bible, we don't use outside sources.... The Bible is sufficient for helping us understand the Bible. No one else is going to tell us what something means. If someone says to us that "forever" [in the verse that describe the conditions for retaining a slave] means "until the jubilee year," you say to them, "That's ridiculous!" and "Why would you say that?"

Note the use of the first-person-plural in every sentence of this passage! He continues:

And thus, Spinoza [insisted] that the Bible is not privileged language, an insistence that I am going to carry through ... in this class, where authoritative interpretations from others will not hold weight. We will use, as Spinoza would say, scripture for interpreting scripture.

With these sentences, Moshe concludes his introduction as a whole.

Now, strictly speaking, Moshe's claim that he and his students will only use "scripture for interpreting scripture" is false. In fact, Moshe used extra-biblical Ancient Near Eastern sources himself, in this very class. ${ }^{22}$ More importantly, setting aside the comparisons to other Ancient Near Eastern texts, the language of "we" and "us" is misleading because Moshe knows that his students do not have the capacity to in-

21 Moshe is referring here to Exodus 21:2-6, which describes the conditions under which a slave may be retained beyond the standard six years of servitude. According to a plain-sense reading of that passage (v. 6), such a slave is retained "forever." However, Leviticus 25:40 seems to indicate that a slave is freed at the jubilee year. These two contradictory passages are reconciled by the midrashic claim (Mekilta De-Rabbi Ishmael 3.17) that "forever" in the first passage means until the jubilee year.

22 It is also worth noting that scholarship always builds on a tradition of inquiry by others, even as it constructs new understandings, so it is never simply a matter of using "scripture for interpreting scripture." 
terpret biblical texts independently. The idea that "the Bible is sufficient for helping us understand the Bible" is all well and good, but of course it requires deep background knowledge of Bible and about Bible to even imagine doing so.

So the idea of the Bible as a self-interpreting text is somewhat disingenuous. But setting this claim aside, we ought to focus our attention on other arguments in these passages, arguments just under the surface. First, of course, there is the argument about the internal diversity of the text, in pursuit of the pedagogic objective of fostering appreciation of diversity. The specific target against which Spinoza is being wielded, the specific "outside sources" that Moshe rejects, are those midrashic sources that harmonize disparate texts, as in his example of the meaning of the word "forever." The second argument, then, concerns the very concept of "privileged language" which is being rejected. The opposite of privileged language is language that is not privileged, language that is mundane, language that is merely human. But human language is open to criticism by other humans. In other words, the second argument reinforces the pedagogical objective of establishing critical distance from the text.

But the third implicit argument in this concluding passage is the most intriguing. Earlier I noted Moshe's use of personal voice. But by using the plural here, he is not only introducing his own persona into the discussion but the personae of his students as well. It doesn't really matter whether Moshe uses extra-biblical material. In fact, it doesn't really matter whether the students can interpret it, on their own, without outside sources. What matters is that Moshe is sending a message about selfreliance, about autonomy. When he talks about "we" here, he draws the students into a worldview in which one trusts one's own reading of a text and one does not blindly accept the authority of other interpreters-a worldview, Moshe believes, that should be embraced by modern Jews.

And Moshe is communicating a message about the journey that they are about to undertake. In case any of them is worried about this class-feeling insecure, doubting the wisdom of doing something that they might think is religiously questionable-Moshe is reassuring them, encouraging them. He tells them, in effect, "We can do this, together!" We can access this text. We can use our minds to interpret this text. Indeed, we can make meaning of this text-not the same meaning that traditional interpreters have made, perhaps, but meaning, even personal meaning, nonetheless. 


\section{Conclusion: Differences within commonalities}

The preceding close analyses corroborate my claim about seven features common to Moshe's teaching in both settings. These seven features are specifically related to the study of Bible-not necessarily exclusive to this subject but not generic either. In other words, they are features of subject-specific (and indeed orientation-specific) pedagogy, and the analysis has been enriched by close attention to the subject and the orientational context. But along the way, it has also become apparent that there are some subtle differences within the commonalities. Only via the comparison do we begin to achieve a richer understanding of some of the possibilities inherent in teaching Bible within the Contextual Orientation, some of the choices available. Consider, first, the three features of Moshe's teaching that I called "pedagogic values."

\section{Awareness of the Problematic Nature of the Subject}

In Bible 101, Moshe expresses this awareness when he acknowledges that some students might believe that his approach to the text is "antireligious," before proceeding to deny that it is so. In B4A, this awareness is expressed more subtly, in his acknowledgement that his central claim, about Israel as a latecomer nation, is "odd," but nonetheless true. To be sure, in referring to Spinoza, Moshe calls attention to Spinoza's status as an excommunicated heretic, implicitly acknowledging that this approach is problematic. But he does not feel the need to explicitly deny any destructive intentions. Perhaps the setting of adult Jewish education changes the dynamic. Perhaps, that is, Moshe does not feel the need to head off misunderstandings of his supposed anti-religiosity in a setting in which he is teaching adult members of his own community, on his own time.

\section{Promotion of the Centrality of Text}

In Bible 101, Moshe turns to biblical texts very early in the class, asking the students to consider them as evidence for the diversity of voices within the text on "profound" issues. In B4A, on the other hand, he does not actually ask the students to study any biblical texts. Instead, this value is expressed through his use of other, non-biblical texts from the Ancient Near East. 


\section{Use of Personal Voice}

Moshe's use of personal voice emerges most dramatically in his signature line, "I teach the Bible; I did not write the Bible. I am not responsible for all the thoughts that the Bible contains." In addition, in B4A we saw a different example of his use of personal voice, in which he encourages the students to join him on his path by using the first-person plural: "no one else is going to tell us what something means."

Next, consider the four features that I described as Moshe's "pedagogical objectives."

\section{Fostering Appreciation of the Internal Diversity of the Text}

In Bible 101, the examples used to demonstrate internal diversity are the "profound" or "relevant" issues of God, death, and gender. In B4A, on the other hand, Moshe uses the more typical (because historically significant) examples of the two versions of the Decalogue and the contradictory slave laws.

\section{Subverting Preconceptions about the Text}

In both classes, it is clear that this objective is centrally important to Moshe's teaching, but the specific preconceptions in question are different. In Bible 101, he subverts the preconception, first and only implicitly, of the Bible's irrelevance; second, of the Bible's unity; and third, moving from the nature of the Bible to its thematic contents, of the Bible's conception of God. In B4A, on the other hand, he subverts the preconception that the Bible's presentation of the history of ancient Israel is trustworthy-not on specific events but more globally, in terms of Israel's significance on the ancient stage. He also explicitly and quite pointedly subverts the preconception of the uniqueness of ancient Israel.

\section{Establishing Critical Distance from the Text}

In Bible 101, Moshe's signature line ("I teach the Bible, I did not write the Bible...") implicitly encourages the students to consider the possibility that they might disavow some elements in the Bible, thus establishing critical distance from the text. The key idea here is responsibility: stu- 
dents need not feel responsible for the text, at least not in its entirety. In B4A, Moshe accomplishes this pedagogical objective by calling attention to the claim that Israel is a latecomer nation. He thus calls into question the self-representation of the text, opening the door toward reading the text with an awareness of its political agenda.

\section{Preserving the Possibility of Personal Meaning}

In Bible 101, Moshe addresses this objective at the very outset, by organizing his presentation around profound, relevant questions, the very questions on which students might hope to find personal guidance. Later on, he introduces his distinction between "what the Bible meant" and "what the Bible means." In B4A, the moments in which Moshe addresses this objective are subtler. He does so at the very end, in his implicit invitation to his students to join him on the journey that, while untraditional, might still be meaningful. But more dramatically, he advises the students to translate the word Torah as "instruction," and thus implicitly preserves the possibility that they might relate to it as a book of instruction as well.

Some of these differences are the result of conscious choices that Moshe makes in his pedagogy, and others are not (and the reasons behind them are therefore more speculative). But the purpose of the present investigation is not to explore a particular teacher's rationales, or explain the variations by recourse to one or more variables (e.g., the age and life position of his students). Rather, the purpose is to develop a richer and more nuanced account of the Contextual Orientation, of its pedagogical features, and of the choices that teachers do-and mightmake within it. I have not attempted to identify the best way to teach Bible, but hopefully I have enriched our sense of the possibilities within one pedagogic orientation to it.

A teacher may strive to foster an appreciation for the internal diversity within the text-but she may now see that there are at least two different kinds of diversity between which she may choose. A teacher may be committed to subverting the preconceptions of her students-but she may now see a number of different possible preconceptions that she might want to think about. A teacher might believe that it's imperative 
to establish some critical distance from the text-but she may now see two different models for establishing that distance. And, perhaps most interestingly, a teacher who is committed to the Contextual Orientation may still wish to preserve the possibility of personal meaning-but she may now see two strategies for doing so, and there are surely more.

This chapter is an inquiry into the way one teacher introduces his students to the study of the Bible in two different settings. At the same time, it also introduces (or reintroduces) us to the Contextual Orientation, offering a closer look at something we may have thought we already knew well enough. While this empirical study was not, as I have stated, intended as an argument for or against the use of the Contextual Orientation, it may help others develop their own arguments with greater attention to the particulars of practice. More broadly, I hope that it will serve to make space for other inquiries-for example, about what teachers who are committed to promoting the centrality of the text actually do with texts in their classrooms, or about the different modes of critical distance and committed engagement that teachers of classical Jewish texts strive to establish and how they do so. While new questions about the Contextual Orientation to the Bible have hopefully become visible because of the analysis offered here, this chapter also suggests paths forward for the serious and careful study of numerous orientations in use in the teaching of Bible. 